\title{
The use and misuse of guidance during the UK's coronavirus lockdown
}

\author{
15 June 2020 \\ Tom Hickman ${ }^{1}$
}

\begin{abstract}
During the critical phase of the United Kingdom Government's response to the coronavirus pandemic, between 23 March 2020 and 1 June 2020, the Government relied heavily on guidance published on its official webpage as an authoritative source of instructions and information for the population at large. This article examines the coronavirus guidance in that period and shows how it developed into a powerful sui generis form of emergency regulatory intervention. The article develops a critique of the coronavirus guidance, demonstrating how it elided and obscured the distinction between public health advice and information about legal prohibitions, a phenomenon described as the creation and exploitation of normative ambiguity. This phenomenon meant that the scope of individual liberty was unclear and at times misrepresented. Whilst the coronavirus guidance was drafted to fulfil well-intentioned public health objectives, by implying, even unintentionally, that criminal law restrictions were different or more extensive than they in fact were and by failing accurately to delineate the boundary between law and advice, the coronavirus guidance failed to respect individual autonomy in a fundamental way. The article makes a number of suggestions for ensuring that guidance satisfies minimum standards of clarity and transparency as form of emergency regulation in the future.
\end{abstract}

\section{Introduction}

This paper elucidates and examines a central feature of the United Kingdom Government's response to the early stages of the coronavirus pandemic, namely, the manner that the Government coordinated individual behaviour though a potent fusion of public health advice and criminal law. It did so principally through the creation and publication of a set of guidance documents on the government website which evolved as the crisis unfolded. ${ }^{2}$ The coronavirus webpage was initially a source of information about the virus, sanitary good practice and travel

\footnotetext{
${ }^{1}$ UCL and Blackstone Chambers, with thanks for Abe Chauhan, Tom Poole and Lord David Anderson for valuable comments.

${ }^{2}$ https://www.gov.uk/coronavirus.
} 
advice, but it developed into the central repository of instructions for people in England ${ }^{3}$ informing them what they should and should not do during the pandemic. Following the lockdown on 23 March 2020, the coronavirus webpage was used to set out detailed public health advice on social distancing as well as an authoritative source of information about the new legal rules. Yet, rather than distinguishing between these two functions, the coronavirus guidance elided them, obscuring the nature of the instructions that the guidance contained. I describe this phenomenon as the creation of normative ambiguity.

In the context of the coronavirus guidance, normative ambiguity refers to the way that the guidance created uncertainty as to whether the instructions that were presented in the guidance reflect rules of criminal law, which people must comply with, or recommended behaviour based on public health advice, compliance with which is ultimately optional. The fusion of law and advice meant that the criminal law aspect of the regulatory scheme had a radiating effect, creating the implication that public health norms were (or may have been) rules backed by criminal sanctions. ${ }^{4}$ The effect of this was to create a situation of overdeterrence because the legal restrictions appeared to be more extensive than they in fact were. As we shall see, from an examination of the periods from 23 March 2020 to 10 May 2020 and from 11 May 2020 to 1 June 2020 which represented the first and second phases of the coronavirus lockdown in England, the normative ambiguity in the coronavirus guidance was exploited (although not necessarily deliberately ${ }^{5}$ ) by the Government to tighten and relax the lockdown, by influencing peoples' perceptions of the degree of individual choice and liberty that they had at different times. Whilst the way that the guidance was drafted was driven by well-intentioned public health objectives, this phenomenon resulted in a real lack of clarity as to what the law required and, more seriously still, by misrepresenting information that framed the choices people made about how to conduct their day-to-day lives during the emergency the coronavirus guidance failed to respect individual autonomy in a fundamental way.

This paper shows that during the first lockdown phase from 23 March 2020 to 10 May 2020, the normative ambiguity in the coronavirus guidance powerfully reinforced the

\footnotetext{
${ }^{3}$ The guidance was initially expressed as advice applicable to the whole of the UK but it was soon limited to England and each regional government now publishes separate own advice on its own webpage. To begin with, the guidance published by the devolved Governments mirrored the UK Government advice, but it has diverged in important respects over time.

${ }^{4}$ In this paper I refer to public health advice. The public health advice promulgated by the Government is obviously a balance of health risks and wider social and economic considerations.

${ }^{5}$ At times, Ministers seemed to be as confused as others as to the distinction between law and advice. Examples of Ministerial statements from the Prime Minister and the Environment Secretary are referred to below.
} 
Government's "stay at home" message by suggesting the legal prohibitions were stricter than they were and that the scope for individual discretion was correspondingly narrower than it in fact was. It will be seen that this approach shifted on 10 May 2020 when the Prime Minister announced in a televised address a policy change from "stay at home" to "stay alert" which was accompanied by the publication of amended coronavirus guidance that had different headline messages. These headline messages were more open-textured and emphasised individual judgment and discretion. Whilst some important changes to the rules were made a few days later, the core legal rules nonetheless remained the same. This important change to the Government's instructions is not therefore explained by any change in the legal rules that the guidance described. Rather, the Government sought to encourage a more permissive attitude to the legal rules. This traded-off the normative ambiguity in the coronavirus guidance in a different way, by emphasising the advisory aspect of guidance and the responsibility of individuals to judge for themselves whether their conduct was appropriate. This potent brew of normative froth exploded spectacularly in the last week in May, when the Prime Minister's chief adviser Dominic Cummings admitted to having left his London residence during the early phase of lockdown for reasons that departed from the coronavirus guidance, but he was quickly backed by the Prime Minister on the basis that he had acted legally and responsibly. ${ }^{6}$ For many people it was incomprehensible how Mr Cummings' actions could be characterised as having been consistent with the law given the stringent instructions that the Government had communicated during the first phase of the lockdown, which set out limited and finite reasons for leaving home. It reflected the confusion created by the conflation of criminal law rules and public health advice coming home to roost.

The paper goes on to suggest that during the period under examination the Government used the fusion of criminal law and public health advice in the coronavirus guidance as a sui generis form of regulatory intervention that sits outside the regime of emergency governance established by Parliament. It shows how this form of emergency regulation failed to conform to basic principles of transparency and clarity and it sets out six principles to which such guidance should conform to ensure transparency and clarity in the future.

This paper proceeds in the following way. Part II explains the phenomenon under discussion taking the headline messages during the first to the second lockdown phase as an example. The paper then goes on in Part III to examine in more detail the various dimensions

\footnotetext{
${ }^{6}$ A. Tolhurst and J. Johnston, "Boris Johnson says Dominic Cummings 'acted legally, responsibly and with integrity' in lockdown row”, Politics Home, 24 May 2020 (available at https://www.politicshome.com/news/article/boris-johnson-saysdominic-cummings-acted-legally-responsibly-and-with-integrity-in-lockdown-row [Accessed 4 June 2020]). See discussion below in Part IV.
} 
of the fusion of law and public health advice embodied in the coronavirus guidance in the period between 23 March 2020 and 1 June 2020. Parts IV and V examine the implications of this method of emergency government and makes recommendations for the future.

\section{The exploitation of normative ambiguity and the first lockdown relaxation}

On 23 March 2020 the Prime Minister in a televised address announced the most stringent restrictions on liberty probably ever imposed in the United Kingdom. He said that the measures came into effect immediately and that the police would have power to enforce the rules. Following the Prime Minister's address, the UK Government's website was changed to include the following headline rules, reproduced at the head of each page of the coronavirus guidance thereafter:

\section{Stay at home}

- Only go outside for food, health reasons or work (but only if you cannot work from home)

- If you go out, stay 2 metres (6ft) away from other people at all times

- Wash your hands as soon as you get home

It then instructed people not to meet others, even friends or family.

On one level this was extremely clear. The instructions to the population were simple and straightforward. But there was a serious ambiguity lurking not far beneath the surface. The first instruction referred to a legal obligation, breach of which was a criminal offence. ${ }^{7}$ The second and third instructions were not legal obligations but public health advice. In terms of the 2 metre guidance, a clear statement of the status of that guidance as public health advice was later to be found buried in the Government's published coronavirus documentation. It stated that the Government, "recommends trying to keep two metres away from people as a precaution."

\footnotetext{
${ }^{7}$ I address later the fact that the criminal offence was not in created until 26 March 2020. ${ }^{8}$ HM Government, “Our Plan to Rebuild: The UK Government's COVID-19 recovery strategy" (2020) 11 May 2020 CP $239,5.8$.
} 
for more than a short period of time, as much as you can." In other words, the 2 metre guidance was public health advice to be taken into account, rather than a rule to be followed.

Yet by setting the instructions side by side without distinction, the fundamentally different nature of the instructions was obscured. People well understood that the lockdown was enforced by law. There was thus an obvious implication that the instructions were each backed by law. ${ }^{10}$ This was accentuated by the fact that each of the instructions were framed as rules, whereas as we shall see at other times the Government chose to frame parts of the guidance explicitly as "advice". ${ }^{11}$ From the perspective of the ordinary citizen, there was no reason to think that the 2 metre guidance was not a rule of law. In New Zealand, for example, the lockdown rules that came into effect on 24 March 2020, the day after the Prime Minister's televised address in the UK, included a 2 metre distance requirement when people were outside their homes. ${ }^{12}$ This was an enforceable part of the criminal law prohibitions in New Zealand. ${ }^{13}$ The limited empirical evidence currently available indicates that this was in fact what most people thought the law was in the UK as well. A study by Halliday, Meers and Tomlinson has found that whilst $99 \%$ of the people surveyed claimed to know mostly or exactly what activities were permitted under the law during the first phase of lockdown, 94\% of them erroneously thought that intentionally coming within 2 metres of someone outside the home was prohibited by law. ${ }^{14}$ This is a staggeringly high percentage of people who confused public health advice

\footnotetext{
${ }^{9}$ HM Government, “Our Plan to Rebuild: The UK Government's COVID-19 recovery strategy” (2020) 11 May 2020 CP 239 , Annex A.

${ }^{10}$ The impression was not dispelled, indeed was reinforced, by the body of the guidance as explained in Part III Bi.

${ }^{11}$ A note on rules: It is sometimes said that a rule embodies an additional reason for compliance beyond its perceived intrinsic merit, namely that it is an injunction that has been expressed by an authoritative source. However, the same could be said of public health advice. For present purposes, I take the difference between rules and advice to be that advice, unlike a rule, permits a person to exercise judgment as to whether or not to follow it or whether it is inappropriate in the circumstance or outweighed by other considerations, whereas a (legal) rule is mandatory and must be followed. As Lord Clarke stated in $R$ (Alvi) v SSHD [2012] UKSC 33, [2012] 1 WLR 2208, at [120]: "as a matter of ordinary language, there is a clear distinction between guidance and a rule. Guidance is advisory in character; it assists the decision maker but does not compel a particular outcome. By contrast a rule is mandatory in nature; it compels the decision maker to reach a particular result.”
}

12 Section 70(1)(f) Health Act Order dated 3 April 2020 provided that persons are required "to maintain physical distancing" outside their residences (para 1(b)), and this is defined as meaning not being within 2 metres of other people (or if within 2 metres being there for less than 15 minutes) (available at https://www.health.govt.nz/our-work/diseases-and-conditions/covid19-novel-coronavirus/covid-19-current-situation/covid-19-epidemic-notice-and-health-act-orders [Accessed 4 June 2020]).

${ }^{13}$ Businesses in Scotland, certain businesses in Wales and burial grounds in Northern Ireland are also required to take reasonable measures to ensure that a distance of 2 metres is maintained between persons on the premises and waiting to enter: Health Protection (Coronavirus, Restrictions) (Scotland) Regulations 2020 (Scottish S.I. 2020/103), regulation 4; Health Protection (Coronavirus, Restrictions) (Wales) Regulations 2020 (Wales S.I. 2020/353 (W. 80)), regulations 4 and 6; Health Protection (Coronavirus, Restrictions) (Northern Ireland) Regulations 2020, regulation 4A (Northern Irish S.I. $\underline{2020 / 55)}$.

${ }^{14}$ S. Halliday, J. Meers and J. Tomlinson, "Public Attitudes on Compliance with COVID-19 Lockdown Restrictions", U.K. Const. L. Blog, 8th May 2020 (available at https://ukconstitutionallaw.org/2020/05/08/simon-halliday-jed-meers-and-joetomlinson-public-attitudes-on-compliance-with-covid-19-lockdown-restrictions/ [Accessed 4 June 2020]). 
for a legal rule, more especially given that it occurred amongst people who claimed to have a high degree of confidence that they knew what the law was.

The fusion of law and guidance thus gave the criminal law a radiating effect on surrounding public health advice. Whilst the messaging appeared to be clear it in fact conveyed highly imperfect information as to the true nature of the instruction being given. ${ }^{15}$ The result of such imperfect information being conveyed is that it results in overdeterrence, which in the present context means people restricting their activities and social contact believing the legal risks to be different to or greater than they in fact are. At one level such effects might be relatively minor. Consider for example a person who, thinking it to be a legal requirement, stops and steps aside in the street to ensure they keep a distance of 2 metres from a passer-by although they recognise that the public health risk of such fleeting proximity to be negligible. This is clear example of overdeterrence. Whilst the consequences of this particular example are trivial, the difficulty in maintaining 2 metres social distancing in situations concerning work or travel to work, means that overdeterrence is likely to have an extremely significant impact on social life and economic activity. Indeed, by the end of May 2020 calls were growing from some quarters for the 2 metre "rule" to be changed to a 1 metre rule on the basis of its impacts on the economy. ${ }^{16}$

There is however a second form of normative ambiguity in play which can be illustrated by reference to the same example. The third of the three instructions is less obviously a rule of law since it is far less likely that there would be a law against neglecting to wash your hands when you get home. To a well informed and reflective person who thought seriously about the matter the unenforceability of such a rule would point to it being public health advice rather than a legal requirement. This of course compounds rather than relieves the overall lack of clarity in the three instructions. But just as the legal nature of a norm can have a radiating effect on associated non-legal norms, so the phenomenon can operate in the other direction. By

\footnotetext{
${ }^{15}$ It is possible to dissect the phenomenon of normative ambiguity more precisely to identify two forms of rule contamination of the surrounding public health advice that can occur. This further aspect of the phenomenon depends upon the possibility that a conceptually meaningful distinction can be drawn between public health guidance which takes the form of a public health rule, the advice in respect of which being that the rule should be followed, and public health guidance that is framed as being advisory only (a distinction that resembles the contested rule/principle distinction in jurisprudence). Assuming such a distinction is meaningful, normative ambiguity can also imply that, whether or not law, public health advice is in fact a rule. I leave this further dimension aside in the analysis that follows.

${ }^{16}$ L. Buchan, "Coronavirus: 2 metre distance rule should be reviewed to save hospitality sector, senior Tories tell government", Independent, 30 May 2020 (available at https://www.independent.co.uk/news/uk/politics/coronavirus-2-metre-distancerestaurant-pubs-tory-mps-a9540021.html [Accessed 4 June 2020]); A. Hancock, "UK Pubs call for 2-metre social-distancing rule to be halved", Financial Times, 18 May 2020 (available at https://www.ft.com/content/aa9c043c-61f4-4ad3-b68cff34d738e2e6 [Accessed 4 June 2020]).
} 
presenting advisory norms alongside instructions based on legal rules, without distinguishing between the two, an implication can be generated that the legal rules are in fact public health advice.

This is illustrated by the changes made to the coronavirus guidance and associated messaging following the Prime Minister's second televised address to the country on 10 May 2020. In that address, the Prime minister signalled a relaxation of some of the rules and encouraged people to return to work and to leave their house to spend time outside. After the address, and before any changes were made to the underlying law, the Government removed the three-point headline instruction set out above and replaced it with the following text:

\section{Stay alert}

We can all help control the virus if we all stay alert. This means you must:

- Stay at home as much as possible

- Work from home if you can

- Limit contact with other people

- Keep your distance if you go out (2 metres apart where possible)

- Wash your hands regularly

Underneath these instructions it was stated that people should not leave their home if a person in the household has symptoms.

The first of the two bullet point instructions reflected legal requirements, the other three reflected public health advice. The emphasis shifted from clear firm injunctions to rules that involved personal discretion and which were framed in far more advisory terms. The overall message was also much more complex, suggesting a greater role for individual assessment. Rather than being told to stay at home apart from limited exceptions, people were told to stay at home "as much as possible". Compared to the previous instruction this represented a widening of the circumstances in which you could leave home and certainly one that conferred greater discretion on individuals to judge. Rather than people keeping 2 metres apart "at all times" the Government also adopted the more open textured and less emphatic requirement keep 2 metres apart "where possible". The references to following the guidance "where possible" also emphasised an aspirational aspect: and that people ultimately had to judge how strenuously to attempt to comply with the rules and the extent to which they were applicable in the particular circumstances. A very vague instruction was also introduced, namely, to "limit contact with other people". Not only was this extremely imprecise but it implied that some 
contact with other people was acceptable (particularly when contrasted with the previous instruction not to meet anyone, even friends or family). The clear injunction to wash hands as soon as you get home also became the unspecific and advisory "wash hands regularly".

Each of these changes taken on their own would have been of little significance. But taken together the changes transformed the impression given of the instructions. Now the instructions appeared to be very much in the nature of recommendations or advisory norms. This exploited normative ambiguity in the coronavirus guidance in a different way, by creating the implication, in these headline messages, that even legal rules were advisory. Previously public health advice had been hardened by its juxtaposition with legal rules, subsequently legal rules were softened by their juxtaposition with public health advice. The difference was created by the subtly different ways the rules and advice were described and presented. Since it is the nature of advice that it places responsibility on individuals to exercise judgement as to whether they consider it appropriate to follow the advice in the circumstances, this change would have had an enabling and empowering effect on individuals. Importantly, these changes to the instructions are not explained by or reflected in any material change to the criminal law. The marked change in instructions communicated to the population resulted from a change in the Government's public health advice and not from any change in the law.

This shift in approach was reflected in the change in message from "stay home", designed to render the population inert, to the more active and empowering "stay alert". This enabling message was graphically reinforced from a vivid colour change in the Government's visuals from red (= stop) to green $(=$ go $) .{ }^{17}$

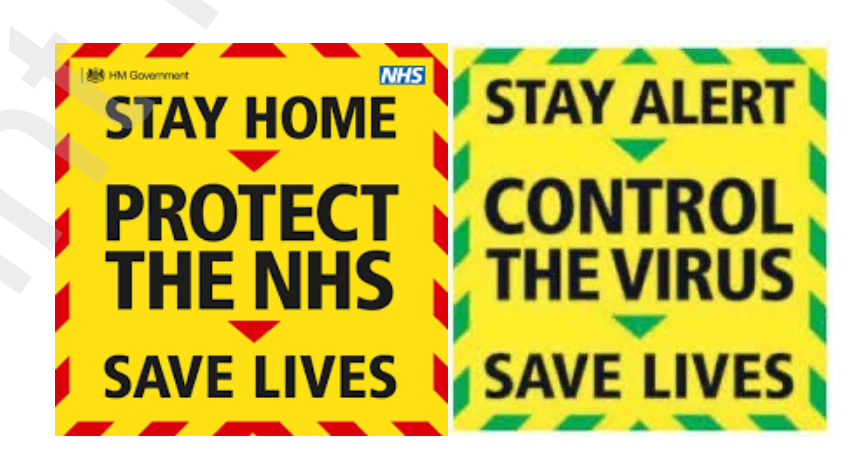

Fig: The UK Government's coronavirus message before and after 10 May 2020

${ }^{17}$ My analysis of the messaging draws on insights of Mike Galsworthy in a video published on Twitter (available at https://twitter.com/mikegalsworthy/status/1259496040522186753 [Accessed 4 June 2020]). 
The televised address given by the Prime Minister on Sunday 10 May 2020 also exploited the normative ambiguity in the guidance in several respects, to suggest that bonds were being untied and freedoms gradually restored. Thus, the Prime Minister announced that as of 13 May 2020, "we want to encourage people to take more and even unlimited amounts of outdoor exercise" and stated that, "you can drive to other destinations" to take such exercise. He also stated, "you can play [outdoor] sports but only with members of your own household". These statements exploited normative ambiguity because they implied that the legal rules were being changed when in fact each of these activities was already permitted. Many people would have thought these activities to have been prohibited (or at least been sufficiently unclear as to whether or not they were prohibited to have been deterred from such activities). It is quite possible that this and other Ministerial statements themselves reflected a muddled understanding of the relationship between public health advice and legal rules.

Consider the first of the quoted statements of the Prime Minister. The coronavirus guidance had stated that only one form of exercise could be taken per day. But this was public health advice not law. Many people, of course, would have assumed that this was law because it was commingled with information about the criminal law. ${ }^{18}$ So whilst the Prime Minister's statement that people were being encouraged to take unlimited exercise accurately alluded to the fact that previously this had been discouraged, most people would have understood this to have been a change in the legal rules. The second and third statements were presented as changes in what persons were entitled to do but there had in fact been no restriction on driving to take exercise or playing sport outside with your household, such as football in the park. ${ }^{19}$ It later became clear that the Government would be allowing outdoor sports courts and venues to reopen and for people to engage in "recreation" for health reasons as well as "exercise", genuine changes, but even taking this into account the Prime Minister's statement suggested the rule relaxations were more extensive than they in fact were. ${ }^{20}$

\footnotetext{
${ }^{18}$ For inexplicable reasons, it was part of the legal prohibitions in Wales (Health Protection (Coronavirus Restrictions) (Wales) Regulations 2020, regulation 8(2)(b)) and was later replaced by a requirement to exercise in the local area on 11 May 2020 (Health Protection (Coronavirus Restrictions) (Wales) (Amendment) (No. 3) Regulations 2020, regulation 2(4)(b)).

${ }^{19}$ The absence of a law prohibiting driving to take exercise was reflected in guidance published by the National Police Chief's Council on reasonable excuse, published after some police forces were reported as discouraging people from travelling to open spaces. The guidance is no longer published but see D. Shaw, "Coronavirus lockdown: Police guidelines give reasonable excuses to go out”, BBC News, 16 April 2020 (available at https://www.bbc.co.uk/news/uk-england-52312560 [Accessed 4 June 2020]).

${ }^{20}$ The Prime Minister then emphasised that in enjoying these new freedoms "you must obey the rules on social distancing. And to enforce those rules we will enforce the fines on those who break them." What however are the "rules on social distancing" that the Prime Minister was referring to? The most obvious "rule" on social distancing is the 2 metres guidance
} 
The purpose of the change in the guidance on 11 May 2020 was clearly to encourage people to exercise greater freedom of action and to take greater personal responsibility for assessing whether their actions are appropriate. Within two weeks of the changes being made it was apparent that people were taking a far more flexible view of the rules, meeting in parks and gardens and exercising their discretion in making what they regarded as appropriate socially distanced contact with other people. ${ }^{21}$

Let us now turn to examine the respects in which normative ambiguity was present in the guidance in more detail.

\section{The fusion of law and pubic health advice in the coronavirus guidance}

\section{A. Information, advice and law}

Until 23 March 2020, the Government pursued an explicitly advisory approach to tackling the coronavirus pandemic. The Government response took the form of travel advisory notices issued by the Foreign Office and advice on personal hygiene issued by NHS England. In the early stages such information was published on the Government coronavirus webpage together with information on the number of confirmed UK cases. On 12 March 2020 advice was added on what to do if you developed symptoms. ${ }^{22}$ As events unfolded in subsequent days, more extensive travel advice and information on consular assistance was added as well as specific guidance for increasing numbers of organisations. ${ }^{23}$ On 16 March 2020 the Government published more wide-ranging advice addressing social distancing, particularly for persons over seventy years old and those with certain underlying health conditions. Everyone was advised

and this was clearly what the reference was to, as well as possibly the prohibition on gatherings. However, as explained, the 2 metres guidance is not an enforceable rule.

21 T. Ball et al, "Easing lockdown: UK rushes back to work and play", The Times, 13 May 2020 (available at https://www.thetimes.co.uk/article/coronavirus-britain-rushes-back-to-business-jfrdzf79t [Accessed 7 June 2020]); S. Morris et al, "Crowds return to beauty spots in England as coronavirus lockdown eases", The Guardian, 13 May 2020 (available at https://www.theguardian.com/world/2020/may/13/crowds-return-england-coronavirus-lockdowneases [Accessed 7 June 2020]); R. Wright, A. Bounds and W. Wallis, "Workers stoical as easing spurs fears of overcrowding", Financial Times, 13 May 2020 (available at https://www.ft.com/content/ef57d543-22aa-4a68-9122-6287caef1a74 [Accessed 7 June 2020]).

22 The self-isolation guidance was initially called the "stay at home" guidance but this was later changed when stay at home became the general message.

${ }^{23}$ Eg 13 March 2020. 
to work at home where possible, avoid gatherings, including with friends or family, avoid pubs and restaurants and vulnerable people were advised to withdraw from social contact altogether. The guidance confidently stated that the "advice is likely to be in place for some weeks".

At this point, it appeared as if the Government would seek to navigate the emergency without resort to legal compulsion, a model followed in Sweden. But that abruptly changed on 23 March 2020 when the lockdown measures were announced by the Prime Minister and the nation was instructed to stay at home under compulsion of law. The coronavirus guidance was updated to include "guidance on staying at home and away from others". The guidance gradually became more extensive, covering a range of topics. A FAQs section was created on 29 March 2020 and has been frequently updated. By 31 May 2020 the coronavirus guidance addressed topics such as self-isolation for persons with symptoms of coronavirus, employment and financial support as well as schools and childcare. The lockdown rules on that date were presented in the section on "Stay alert and safe: social distancing guidance for everyone" an evolved version of the original guidance on staying at home, and in the section entitled "Stay alert: what you can and can't do", a development of the FAQ section. Whilst the guidance was initially UK-wide, on 28 March 2020 it provided links to the websites of the three regional governments which contain separate guidance applicable in Wales, Northern Ireland and Scotland.

The legal basis for the promulgation of the coronavirus advice was not mentioned on the website but the Secretary of State for Health has power to provide "information and advice" to the public for the purpose of "protecting the public in England from disease". ${ }^{24}$ The legal status of such information and advice is that it is non-binding. It does not have the force of law and therefore is not enforceable in the courts. No sanctions attach to a failure to follow information or advice issued under statutory powers. The framing of information or advice as "guidance" does not change its character. In Laker Airways Ltd v Department of Trade, Roskill LJ stated that, "guidance is assistance in reaching a decision proffered to him who has to make that decision, but that guidance does not compel any particular decision" 25 and Lawton LJ noted that guidance "has the implication of leading, pointing the way...". ${ }^{26}$

\footnotetext{
${ }^{24}$ National Health Service Act 2006 section 2A. It is not known if this was the power that the Government has relied upon in promulgating the coronavirus guidance but it is the most likely candidate.

${ }^{25}$ [1977] QB 643, 714.

${ }^{26}$ [1977] QB 643, 725; R (Alvi) v SSHD [2012] UKSC 33, [2012] 1 WLR 2208 at [120] ; $R$ v Director of Passenger Rail Franchising, ex p. Save Our railways, [1996] CLC 589, 597 (Macpherson J): "Guidance is advice which the recipient should heed and respect; it should ordinarily be followed but need not if there are special reasons for hot doing so."
} 
The increasing use of advice and guidance as a method of governance has resulted in increased jurisprudence on the topic. The promulgation of advice or guidance is to be distinguished from the situation where government publishes a policy with the objective of regulating how public officials will exercise discretionary powers. ${ }^{27}$ Guidance and advice is, by contrast, promulgated not to regulate a public authority's exercise of its own power, but for the benefit of external bodies or private individuals. ${ }^{28}$ The cases establish that a public authority can in an appropriate case provide guidance to "explain, amplify or supplement" the law, but it cannot contradict the objectives of a statute or misstate the law. ${ }^{29}$ If it does so, this will be an error of law that the courts will declare to be erroneous if a claim is brought before them by an interested citizen. In BAPIO Action, the House of Lords went further and ruled that guidance published by the Department of Health seeking to persuade NHS trusts to impose conditions on the recruitment of international medical graduates was unlawful essentially because it was being used to restrict immigration status without going through the formal process of changing the immigration rules. ${ }^{30}$ By comparison with the jurisprudence on polices, the law on published guidance nonetheless remains underdeveloped.

The Secretary of State for Health has a separate and distinct power to issue regulations to combat outbreaks of disease under the Public Health (Control of Disease) Act 1984. Pursuant to this power, the Secretary of State issued the Health Protection (Coronavirus, Restrictions) (England) Regulations 2020, S.I. 2020/350 (“the Regulations”), requiring certain businesses, premises and facilities to close or restrict their operations, and requiring people to stay at home. ${ }^{31}$ The Regulations also prohibited gatherings in public places of more than two people from different households.

\footnotetext{
${ }^{27}$ As to which see Madalia $v$ Secretary of State for the Home Department [2015] UKSC 59, [2015] 1 WLR 4546; R (Lumba) v Secretary of State for Home Department [2011] UKSC 12, [2012] 1 AC 245.

${ }^{28}$ In practice the distinction between policy and guidance is often blurred.

${ }^{29}$ [1977] QB 643, 699 (Lord Denning MR). Lord Bridge in Gillick v West Norfolk and Wisbech Area HA [1986] AC 112, 193 stated: "We must now say that if a government department, in a field of administration in which it exercises responsibility, promulgates in a public document, albeit non statutory in form, advice which is erroneous in law, then the court, in proceedings in appropriate form commenced by an applicant or plaintiff who possesses the necessary locus standi, has jurisdiction to correct the' error of law by an appropriate declaration."

${ }^{30}$ Because for instance international medical graduates were not debarred from work in private hospitals at whom the guidance was not directed. See $R$ (BAPIO Action Ltd) v Secretary of State for the Home Department [2008] UKHL 27, [2008] 1 AC 1003.
}

${ }^{31}$ For a discussion of the Regulations see T. Hickman, E. Dixon and R. Jones, "Coronavirus and Civil Liberties in the UK", Blackstone Chambers COVID-19: Legal Insights, 6 April 2020 (available at

https://coronavirus.blackstonechambers.com/coronavirus-and-civil-liberties-uk/ [Accessed 4 June 2020]) and T. Hickman, 'Eight ways to reinforce and revise the lockdown law', U.K. Const. L. Blog, 15 April 2020 (available at https://ukconstitutionallaw.org/2020/04/16/tom-hickman-eight-ways-to-reinforce-and-revise-the-lockdown-law/ [Accessed 4 June 2020]). 
The Regulations came into effect at 1pm on 26 March 2020 and very similar regulations came into effect in other parts of the United Kingdom shortly thereafter. ${ }^{32}$ The legal rules set out in the Regulations were backed by fines and enforcement powers, including the power of arrest and the power for the police to return people by force if necessary to their homes. The Regulations had to be approved by Parliament (in the case of the Welsh, Northern Irish and Scottish regulations, by the relevant devolved legislature), although since the urgency procedures in the 1984 Act were used such approval occurred well after the regulations were made. ${ }^{33}$ The Regulations were first substantially amended on 13 May 2020, most notably to allow people to leave home to engage in recreation for their physical or mental wellbeing rather than just to take exercise. ${ }^{34}$ A further substantial amendment occurred on 1 June 2020 when the Regulations were changed to remove the requirement that people stay in their home (but to prohibit people staying overnight outside their home) and allowing gatherings of up to six people. ${ }^{35}$ The present analysis is concerned with the period up to the change on 1 June 2020 although much of the analysis is pertinent to the subsequent period as well.

The core provisions enforcing the stay at home rules were contained in regulation 6 of the Regulations. Regulation 6 provided, as enacted, that: "6.-(1) During the emergency period, no person may leave the place where they are living without reasonable excuse." Subsection (2) then provided that "a reasonable excuse includes the need" to "obtain basic necessities, including food and medical supplies for those in the same household (including any pets or animals in the household) or for vulnerable persons and supplies for the essential upkeep, maintenance and functioning of the household, or the household of a vulnerable person, or to obtain money, ..." (6(2)(a)). It also included the need: "to take exercise either alone or with other members of their household". A number of other specific excuses were also listed, including to seek medical assistance, to travel for work or provide voluntary services where this was not reasonably practicable to be done from home.

\footnotetext{
32 See above note 11 for the references. The Northern Ireland regulations were made pursuant to the Public Health Act (Northern Ireland) 1967 and the Scottish regulations pursuant to Schedule 19 of the Coronavirus Act 2020. The Welsh regulations came into effect at 4pm on 26 March 2020, the Scottish regulations at 7.15pm on 26 March 2020 and the Northern Irish regulations at $11 \mathrm{pm}$ on 28 March 2020.

${ }^{33}$ Since Parliament had risen for recess before the Regulations were laid, a motion for their approval was not debated by the Commons until 4 May 2020 and was not approved by the Lords on 14 May 2020.

${ }^{34}$ Health Protection (Coronavirus, Restrictions) (England) (Amendment) (No. 2) Regulations 2020/500 regulation 2(3)(a).

${ }^{35}$ Health Protection (Coronavirus, Restrictions) (England) (Amendment) (No. 3) Regulations 2020/558 regulation 2(8), although it did introduce reasonable excuses for doing so, for example to attend the funeral of a close family member (regulation 2(6)).
} 
There are therefore two entirely separate power sources that underpinned the coronavirus guidance: a power for the Secretary of State to issue regulations setting out new criminal laws and a power to issue non-binding information and advice. Neither of these powers are specifically emergency powers.

The decision to make some requirements set out in the coronavirus guidance a matter of law and others advice was probably in part influenced by limits on the Secretary of State's powers to make regulations under the 1984 Act. So, for example, the Secretary of State is expressly prevented from using regulations to impose quarantine obligations on people thought to be infected with disease: quarantine must be imposed by a magistrate, so the rules on selfquarantine for 7 or 14 days where persons exhibit symptoms of Covid-19 could not be made enforceable under the 1984 Act and therefore had to be advisory. ${ }^{36}$ But this is not a complete explanation for why some rules were advisory and some were founded in law, even in relation to the core social distancing rules. The 2 metre guidance, for instance, probably could have been made a legal condition on persons being outside their home. ${ }^{37}$

Having identified the underlying power sources for the coronavirus guidance we now look more closely at the coronavirus guidance itself.

\section{B. Forms of ambiguity in the coronavirus guidance}

It is possible to identify at least three different types of instruction contained in the coronavirus guidance. First, the guidance set out public health advice. This, as has been explained, had no legal force and at most could have given rise to social opprobrium for those who chose not to follow it. ${ }^{38}$ Secondly, the coronavirus guidance contained information about

\footnotetext{
${ }^{36} 1984$ Act, ss.45F and 45D(3). The Government would have needed to enact primary legislation for the more general self isolation rules directed at infected or symptomatic persons to be enforced by the criminal law, or to have used the Civil Contingencies Act 2004. Notably, when the Government introduced a fourteen day quarantine for persons entering England, on 8 June 2020, the quarantine provisions were set out in law (The Health Protection (Coronavirus, International Travel) (England) Regulations 2020) reflecting the fact that the Secretary of State had power enact criminal law provisions enforcing self-isolation and quarantine under s.45B of the 1984 Act when this concerned a danger to public health from aircraft, vessels or vehicles arriving in the country.

${ }^{37}$ On the government's broad interpretation of section $45 \mathrm{G}(2)(\mathrm{j})$ of the 1984 Act a prohibition on persons being within 2 metres of each other would seemingly have been possible as a restriction on where a person goes and with whom he has contact. The New Zealand rule is cited above at note 10 .

${ }^{38}$ This statement requires some qualification, particularly in the context of employers and other persons who owe a duty of care to others. In such a context, public health advice can have important indirect legal effects by framing judgements about what constitutes reasonable steps to take to comply with a duty of care. A person or business that follows public health advice is likely to be able to make out a good defence in fact to a charge of negligence. Compliance with government guidance is also likely to be required or prudent to ensure compliance with business and premises insurance policies. This aspect of the fusion of law and guidance and the ability for guidance to have indirect legal effects represents a very important part of the way that guidance can in practice enforce social distancing measures. The correlation between guidance and legal liability is not, however, direct and many businesses in the UK had taken steps going beyond the government guidance well before there was
} 
the legal rules imposed by the Regulations. This information constituted (or purported to constitute) descriptive statements of the law. For example, it recorded legal rules requiring restaurants and cafes to close. Such statements might of course be simplified descriptions of the legal rules. Thirdly, the coronavirus guidance contained statements which represented the Government's interpretation of the law or its view as to how the law should be applied. Examples included what constituted "exercise".

This third aspect of the guidance is more controversial than the first two because the interpretation of the criminal law is not a matter for the government. Under the UK's constitutional arrangements, the Government has no role in interpreting or enforcing the law those functions belong to bodies independent of government: the courts and the police and prosecution authorities respectively. Indeed, it is central to our constitution that the Government cannot either purport to dispense with criminal laws, including by committing to not enforcing them in certain situations, or introduce new ones without the sanction of Parliament. ${ }^{39}$ The Government's statements on what the law requires are therefore opinions which cannot provide a defence to prosecution, still less widen the ambit of a criminal prohibition. Nor are they binding on the police of the Crown Prosecution Service. In practice, however, the government's guidance is likely to be taken into account when enforcement and prosecutorial decisions are made. ${ }^{40}$

Let us now unpick in more detail the various ways in which the coronavirus guidance generated normative ambiguity in the period up to 1 June 2020.

\section{i. $\quad$ Elision of information about the law, legal advice and public health guidance}

The principal source of the normative ambiguity created by the coronavirus guidance was the juxtaposition and in places complete elision of information about legal rules on the one hand and public health advice on the other. No clear lines were maintained between these

\footnotetext{
any advice or direct legal compulsion to do so. Since my focus is on the aspects of the Regulations applicable to private individuals, I leave aside this issue.

${ }^{39}$ See $R$ (Nicklinson) v Ministry of Justice [2014] UKSC 38, [2015] A.C. 657 and $R$ (Purdy) v Director of Public Prosecutions, [2010] 1 A.C. 34 considering the proper constitutional limits on the Director of Public Prosecutions use of guidance in the enforcement of the criminal law and the impact of the Bill of Rights 1688 which prohibits the Crown from suspending the operation of the criminal laws.

40 The College of Policing published separate guidance for police forces in England and Wales in an "Understanding the Law" section of its Coronavirus information on its website, including a useful publication on its views as to the meaning of reasonable excuse (no longer published, see note 17). A collection of advice and guidance is to be found at https://www.college.police.uk/What-we-do/COVID-19/understanding-the-law/Pages/default.aspx [Accessed 4 June 2020].
} 
different types of instruction. It was not possible for people to know, without a high level of sophisticated legal knowledge, whether statements contained in the coronavirus guidance were statements of law, interpretations of the law or public health advice.

Some examples of this have already been provided in Part II. A further example of a pure piece of public health advice in the section "what you can and can't do" was the statement that when using a vehicle to use a journey that is permitted, you should only travel with members of your household. ${ }^{41}$ There were however no legal rules that materially governed the use of private vehicles by two people from different households, e.g. a car share. Despite being presented in emphatic terms, the section of guidance was pure public health advice.

In some instances law and public health advice were interwoven not only in the same section of guidance but in the same sentence. Take the guidance on leaving home to go shopping. Up to 10 May 2020 the coronavirus guidance stated that a person could leave home to go "shopping for basic necessities, for example food or medicine, which must be as infrequent as possible". The statement that a person could leave home for shopping for basic necessities, for example food or medicine, was a statement of the law. But the subsequent statement that this must be as infrequent as possible was not a statement of law it was public health advice.

This elision of law and public health advice was not offset by any clear statement as to what aspects of the guidance were legally enforceable and which were not. On the contrary, the position was quite the reverse. In the section of the guidance setting out the rules requiring persons to stay at home, ${ }^{42}$ after stating that people must be 2 metres apart from anyone outside their household, it stated: "These measures must be followed by everyone". The introductory section of the guidance had also made clear that the police "will be given powers to enforce" the staying at home rules, business closures and prohibition on gatherings. This clearly implied that all of the instructions in the social distancing and stay at home guidance at that time were enforceable despite the fact they included instructions that have never been subject to legal restriction: the 2 metre guidance, the stated limit on exercising only once per day, and the requirement that shopping be as infrequently as possible, were never backed by law.

One particularly striking and significant feature of the coronavirus guidance was that although the lockdown was announced and the guidance was published on 23 March 2020,

${ }^{41}$ Coronavirus Guidance as at 12 May 2020: "1.8 Can I share a private vehicle with someone from another household? No. You can only travel in a private vehicle alone, or with members of your household."

${ }^{42}$ Eg 25 March 2020. 
until 1pm on 26 March 2020 there were no regulations in place to underpin them. For several critical days, the entire regime was advisory. The Regulations were not even published in draft form before they were made so nobody outside government had any idea what legal regime underpinned, or was going to underpin, the guidance. Public lawyers and criminal lawyers spent the period between 23 March and 26 March 2020 perplexed as to what laws the Government could be using to enforce the rules. On 26 March 2020 it became clear that there had been none. The UK lockdown was based on a gigantic bluff.

A cynical and sophisticated reader of the guidance might have picked up the deliberate nuance in the words quoted above, in the first post-lockdown form of the guidance. By stating that police "will be given" power to enforce the rules, the guidance nodded to the fact that they did not, at that time, have such power. Most people would however simply have taken this to be making clear that the instructions, although based on law, would be subject to greater police powers. After all, the coronavirus guidance also stated that the "measures are effective immediately" and the "measures must be followed by everyone". The reality, however, was very different. Nobody was required to follow them.

After the Regulations were published and came into effect the task of seeking to relate them to the instructions in the coronavirus guidance represented a complex and technical exercise. ${ }^{43}$ There was no alteration to the structure or wording of the coronavirus guidance to separate or identify those parts that were enforceable under the Regulations. ${ }^{44}$ The clear impression given was that the rules set out in the guidance on staying at home were backed by law, when in fact important aspects of the instructions were not and reflected public health advice. This is how the coronavirus guidance remained throughout the critical period of late March and April. ${ }^{45}$

\footnotetext{
${ }^{43}$ See Hickman, Dixon and Jones "Coronavirus and Civil Liberties in the UK", Blackstone Chambers COVID-19: Legal Insights, 6 April 2020 (available at https://coronavirus.blackstonechambers.com/coronavirus-and-civil-liberties-uk/ [Accessed 4 June 2020]) for an analysis published more than a week after the Regulations were published. There was not much else published analysing the Regulations, but see Lord Sandhurst QC, Anthony Speaight QC, "Pardonable in the Heart of the Crisis - But we must urgently return to the Rule of law" Society of Conservative Lawyers, 4 April 2020 (available at https://e1a359c7-7583-4e55-8088-a1c763d8c9d1.usrfiles.com/ugd/e1a359 017552492cac41868ee7eed2a53fe99d.pdf [Accessed 4 June 2020]).

${ }^{44}$ On 26 March 2020, the final section of coronavirus social distancing guidelines was changed to include a statement that if a person leaves home or gathers in a public space "for any reason other than those specified", the police may take action. The purpose of this section appears to have been to warn people that police had powers to disperse gatherings and return people home, rather than being any effort to distinguish laws from advice, which it did not do (it was for example clear that other parts of the guidance other than those referred to were backed by law, such as that relating to the closure of businesses). The reference was actually highly misleading as the guidance only "specified" four reasons for leaving the home when the Regulations listed thirteen in addition to the catch-all "reasonable excuse".

${ }^{45}$ In the question and answer section of the guidance introduced on 29 March 2010 stated:
} 
On 2 May 2020 a change was made to the section addressing police enforcement which represented the first effort to draw attention to the fact that not all of the rules were backed by law. It stated that police authorities "have the power to enforce the requirements set out in law if people do not comply with them." More significantly, it introduced a more prominent statement in the first section of the rules on staying at home which stated that "[k]ey parts" of the measures are "underpinned by law, which sets out clearly what you must and must not do". This at least indicated that not all of the coronavirus guidance was underpinned by law. The reference to "law" included a hyperlink to the government's legislation database (as to which more below).

Even at this late stage, neither statement actually identified which of the instructions were backed by law and which were not and the guidance itself continued to refer indiscriminately to law and public health advice. The exercise of seeking to unpick one from the other was left to individuals to undertake. It is however obvious that the vast majority of people, even if they ventured beyond the news media to read the coronavirus guidance in the first place, would have gone no further and certainly would not have spent time seeking to examine primary legal provisions in their unfamiliar native form in an effort to establish which parts were backed by law. Whilst the references introduced on 2 May have raised doubts in peoples' minds about whether instructions in the guidance were reflective of the criminal law, they were very far from adequate to make clear to the ordinary reader of the guidance which instructions reflected legal obligations and which did not.

There was also a further problem. The coronavirus guidance did not identify the relevant law. The coronavirus guidance referred somewhat cryptically to "law" and "regulations" but the regulations were not identified by name. For an unskilled person to seek to find the relevant regulations would itself be a significant task, more especially as they were amended from time to time. Unfortunately, this difficulty was aggravated by the fact that the two hyperlinked references to "law" (and a further hyperlinked reference to "regulations" introduced in mid-May) hyperlinked to the wrong coronavirus public health regulations. The link was to regulations concerned with detention, isolation and screening of persons suspected of being infected. ${ }^{46}$ This was no doubt mere negligence but the result was that the references

We appreciate all the effort people are putting into containing the spread of coronavirus which will help protect our NHS and save lives.

If you breach the regulations, the police may:...."

The regulations and their contents were not specified. Most people would have taken the reference to the "rules" and the "regulations" be to the coronavirus guidance itself.

\footnotetext{
${ }^{46}$ Health Protection (Coronavirus) Regulations 2020, S.I. 2020/129.
} 
to the "law" and to "regulations" in the guidance were utter gobbledygook. It is perhaps telling that no one appears to have picked up on the error (suggesting nobody followed the links or if they did they soon gave up in despair) as the wrong law was hyperlinked until 13 May 2020. ${ }^{47}$

The net effect was that for a person without specialist legal knowledge and a good deal of time, there was simply no way of countering the incorrect messaging within the guidance by cross-checking the coronavirus guidance with the operative legal provisions.

\section{ii. Glossing legal terms including the "reasonable excuse" exception to the prohibition on leaving home}

As we have seen, the coronavirus guidance included the Government's interpretation of the law as well as information as to what the law was. This took on a particularly important dimension in relation to the core prohibition on people leaving their home because this legal rule was subject to an ambiguous open-ended exception: people could leave and be outside their home if they had a "reasonable excuse". ${ }^{48}$ Whilst the law itself specified certain reasons for leaving home that constituted "reasonable excuses", such as food shopping or going to work, these provisions themselves embodied terms with broad scope for interpretation, perhaps most obviously, the meaning of "exercise", and later "recreation" for reasons of health and wellbeing. But since the list was not exhaustive the overriding legal requirement and therefore the boundary of individual liberty between 26 March 2020 and 1 June 2020 was the concept of "reasonable excuse".

The concept of reasonable excuse admitted a very broad range of possible meanings. It could have been understood to permit only very limited situations in which a person might lawfully be outside their home, such as technical and fleeting instances beyond the list set out in the regulations - stepping off a doorstep to clap the NHS or retrieving an item left in a car parked in the street might be examples - or situations where there is some clear necessity that required a person to leave the house. Alternatively, it could have been understood broadly and by reference to the underlying public health rationale, to allow any non-frivolous activity outside the home that did not give rise to a public health concern, for example, sitting with an easel in the park painting a picture of the sunrise or taking the kids to feed the ducks. Such

\footnotetext{
47 The change may or may not have been prompted by a tweet by the author on 11 May 2020 pointing out that the post- 10 May 2020 regulations included a hyperlink to the wrong regulations.

${ }^{48}$ Regulation 6 of the Regulations.
} 
could be "reasonable" reasons for being outside the house in the context of a pandemic since they allow social distancing to be observed. The concept admitted of a range of interpretations between such outer limits.

Added to these issues of vagueness, the concept was capable of changing over time. This is because the list of permitted activities was relevant to understanding the general exception. The more restrictively the permitted exceptions were framed the more restrictively the concept of reasonable excuse was likely to be understood. As the list of permitted reasonable excuses was adjusted, so the wider concept of "reasonable excuse" was capable of taking on a new form. Thus, after the 13 May 2020 amendments to the regulations permitted people to leave their home for recreation to further their physical or mental wellbeing. Given that people could leave the house for such purposes, it was more obviously reasonable to engage in other activities outside, such as leaving the house to borrow an item from a neighbour or go and sing happy birthday outside a friend's house.

The vagueness of the concept of reasonable excuse and the ambiguity present in other terms thus provided a platform for the Government to provide an overlay of guidance by which it effectively widened or narrowed the exception. Thus, the coronavirus guidance originally portrayed the exception as both finite and exceptionally limited. On 23 March 2020 the coronavirus guidance stated: 49 "You should only leave the house of one of four reasons". It then listed shopping for basic necessities which "must be as infrequently as possible", one form of exercise per day, medical need, and work. That was all.

The statement was inaccurate for a number of reasons. Most fundamentally, as we have seen, at this time there were in fact no legal restrictions in place that could have reflected these four reasons for leaving the house. But even when the regulations came into force several days later, they listed thirteen specific reasons for leaving home as well as the general exception of reasonable excuse. The guidance at this point was changed to state that people, "should only be away from [their] home for very limited purposes". But it then listed the same four purposes and did not refer either to the fact that many other reasons for leaving home were allowed or that any other reasonable excuse was permitted. ${ }^{50}$ Worse, the section of the guidance which posed the question "What will happen to me if I break the rules?" stated that if a person left home "for any reason other than those specified" the police could take action including

\footnotetext{
${ }^{49}$ Under the guidance on staying at home and away from others, "1. Staying at home".

${ }^{50}$ This was also reflected in the pages headed "Staying at home: what you can and can't do" and "Coronavirus FAQs: what you can and can't do" that were added on 29 March 2020.
} 
imposing fines. The guidance was clear: there were four reasons for leaving home and it was an offence to leave home for other reasons.

Indeed, the coronavirus guidance in the relevant period did not use the words "reasonable" or "excuse" at any point. The reason was because the Government wanted to ensure that people stayed at home. That might have been entirely sensible public health advice but the coronavirus guidance created the impression that the law was far more stringent than it was and limited the scope of individual autonomy and liberty to a much greater extent than it actually did.

It was only on 2 May 2020, almost six weeks after lockdown, that the guidance first informed individuals (in the FAQs section) that the four reasons were exceptions "and a fuller list is set out in the regulations." This was however a short and delphic statement. The reference to "the regulations" was unexplained and it was not mentioned that the stated exceptions were examples of a broader exception of reasonable excuse. Moreover, as noted above, this reference was linked to the wrong regulations, namely those concerning the detention, isolation and screening of persons suspected of being infected. So whilst the guidance was less misleading, it was no more informative.

The guidance also provided a narrow and inaccurate description of several of the individual exceptions listed in the Regulations, as has already been touched upon. Thus, in relation to exercise it stated that a person could take "one form of exercise a day, for example a run, walk, or cycle - alone or with members of your household". The messaging was reinforced by Government statements in the media, such as Environment Secretary Michael Gove MP who stated that a walk of up to an hour, a run of 30 mins or a cycle of 30-60 minutes was what the rules envisaged. ${ }^{51}$ This was a very restrictive interpretation of the Regulations, indeed an inaccurate interpretation of them. There was no prohibition on playing games such as golf, football or tennis, doing yoga or stretching in the park, or many other forms of exercise, as long as they were with members of the same household. There was no limit on the length of time a person could exercise or how many times per day they could do so. Despite the breadth of the exception, the Government guidance portrayed it in a very different way. Again, this may have been good public health advice but it departed from the requirements of the law.

${ }^{51}$ J. Johnston, "Michael Gove tells joggers to limit exercise stints to 20 minutes amid coronavirus lockdown", PoliticsHome, 29 March 2020 (available at https://www.politicshome.com/news/article/michael-gove-tells-joggers-to-limit-exercise-stintsto-30-minutes-amid-coronavirus-lockdown [Accessed 4 June 2020]). 
It was not only the exercise exception that was subject to glossing by government guidance. Another example is provided by the guidance on leaving home to go shopping. From 23 March 2020 to 10 May 2020 this stated: ${ }^{52}$

"You should only leave or be away from your home for very limited purposes:

- shopping for basic necessities, for example food and medicine, which must be as infrequent as possible"

This gave the impression of very restrictive rule and indeed that unnecessary trips to the shops would be a criminal offence. ${ }^{53}$ However, in truth the first sentence that follows the bullet point included both a statement of the law (in the first clause) and then a statement of public health advice (in the second). The introductory statement before the bullet point was (a very narrow) interpretation of the exception. This example thus embodies each of the three different types of statement that have been identified above - descriptions of the law, interpretation of the law and public health advice - woven together within the same sentence.

On 11 May 2020 this guidance was changed to read: ${ }^{54}$

"You should stay at home as much as possible. The reasons you may leave home include:

- Going to shops that are permitted to be open - to get things like food and medicine.

This change, though subtle, was significant. The public health advice was still present: it had become "stay at home as much as possible". This was more obviously public health advice. ${ }^{55}$ Reference to the legal rule was also made, but this had changed significantly, so that it

\footnotetext{
52 “Coronavirus outbreak FAQs: what you can and can't do", No. 1.

${ }^{53}$ Cambridge Police announced it had been patrolling a supermarket for shoppers buying non-essential items and the Chief Constable of Northamptonshire Police said that his force would start checking shopping baskets: D. Chipakupaku, "Coronavirus: Cambridge Police checks no one is in non-essential aisles at supermarket", Sky News, 10 April 2020 (available at https://news.sky.com/story/coronavirus-cambridge-police-checks-no-one-is-in-non-essential-aisles-atsupermarket-11971517 [Accessed 4 June 2020]); A. Bienkov, "A police chief threatened to start checking shopping trolleys for 'unnecessary' items during the UK coronavirus lockdown', Business Insider, 9 April 2020 (available at https://www.businessinsider.com/coronavirus-uk-police-chief-threatened-to-check-shopping-trolleys-2020-4? $\mathrm{r}=\mathrm{US} \& \mathrm{IR}=\mathrm{T}$ [Accessed 4 June 2020]).

54 “Coronavirus outbreak FAQs: what you can and can’t do", No. 1.2.

${ }^{55}$ As indicated by the words "as much as possible" and by the separation with the following sentence which sets out a clear statement of a rule and exception.
} 
presented the law in much more permissive terms, emphasising that the reasons for leaving home "include" shopping and is not limited to "basic necessities". These changes were made without there being any change to the underlying legal provisions. It is an example of how the coronavirus guidance at different times presented the same legal provisions in different ways. The reason for the change in presentation was to reflect the Prime Minister's upbeat message in his 10 May 2020 televised address to the nation and to encourage people to take a more permissive view of the rules. Whilst changes to the rules were made a few days later, no changes were made to the law that justified the rephrasing set out above.

An interesting example of the Government adopting the opposite technique - i.e. portraying an exception more broadly than it actually was - is provided by an amendment that was made to the guidance following the threat of legal challenge by parents of children with autism and learning disabilities. The proposed claimants made the point that it was not realistic for them and their children to stay inside other than for exercise once per day. This resulted in a change to the guidance on 8 April 2020. ${ }^{56}$ The FAQs added the question, "Can I exercise more than once a day if I need to due to a significant health condition?" to which the answer was given that you could. If a health condition routinely required a person to be outside their home more than once per day to "maintain [their] health" then that person could continue to leave the house for this purpose. It continued: "This could, for example, include where individuals with learning disabilities or autism require specific exercise in an open space two or three times each day - ideally in line with a formal care plan agreed with a medical professional."

The effect of this use of guidance was to expand the concept of "exercise" beyond any sensible understanding of that concept. The object of the change to the guidance was to permit people with children with health needs to take recreation outside (and probably for the parent's benefit as well as the child's). This was an entirely laudable objective. But it was achieved in a manner that manipulated the role of the guidance by allowing outside activity as exercise that was not in truth within the exercise exception. ${ }^{57}$ Rather than utilise the concept of reasonable excuse, which might have suggested other more wide-ranging exceptions, or amend the Regulations to add a clear and self-standing exception, the Government essentially used the

\footnotetext{
56 "Coronavirus outbreak FAQs: what you can and can't do", No. 15 corresponding to regulation 6(2)(b) of the Regulations.

${ }^{57}$ It might have been better expressed as falling within the exception "to avoid injury or illness" (regulation 6(2) (m) $)$ but this would also require some degree of reinvention as the exception is not directed at avoiding illness but managing long-term existing conditions.
} 
guidance to create an exception that did not exist. This is another example of the Government's presentation of the law being distorted by public health advice.

\section{iii. $\quad$ The portrayal of public health advice as rules}

Another feature of the coronavirus guidance that contributed to the blurring of the relationship between legal obligation and public health guidance was that public health advice was sometimes presented as a recommendation and sometimes presented as a rule. ${ }^{58}$ This exacerbated the ambiguity as to the status of the instruction in question because rules are generally, at least in this context, the product of law and certainly give the impression that they must be followed. The various different ways that different instructions self-described contributed to the overall level of confusion as to the nature and status of the instructions that coronavirus set out.

\section{Implications of the fusion of law and guidance}

The previous discussion has shown how in the critical period between 23 March 2020 and 1 June 2020 the coronavirus guidance elided the criminal law and public health advice, obscuring the nature of the instructions given to the population. This was not a unique feature of the English coronavirus guidance and was seen in the relevant guidance in other parts of the UK. This is partly a reflection of the fact that the regional governments adopted the central UK guidance and extremely similar lockdown regulations were introduced at the same time in each region. Many of the examples discussed in this paper are therefore also found in the guidance promulgated by the regional governments. For example, the Scottish Government also stated in its guidance that exercise could only be taken once a day, whereas this was no more a legal requirement in Scotland than in England. On 11 May 2020 the Scottish Government announced an easing of the lockdown and changed its guidance to state that exercise could be taken "as often as you like, as long as you observe social distancing rules". This appeared under the statement that you should only leave home "for very limited purposes", a carry-over from the

${ }^{58}$ For example, the Coronavirus Guidance 11 April 2020 stated:

Rule: "if you live alone and have symptoms of coronavirus illness (COVID-19), however mild, stay home for 7

days..."

Rule: "If you go out, stay 2 metres away from other people at all times..."

Cf. Advice: "We advise you to stay local and use open spaces near to your home were possible..." 
UK Government guidance. For most people, this would have appeared to be a change in the law, a view reflected in the headline of The Scotsman newspaper which read, "First Minister lifts exercise rule in Scotland's lockdown" with the strapline, "Scots will now be allowed to go out more than once a day". ${ }^{59}$ But the law had not changed, only the public health advice. Scots had always been allowed to go out more than once per day to exercise. Similarly, the reference to "social distancing rules" (and an accompanying video showing individuals outside the house with 2 metres radius circles around them) suggested that compliance with the 2 metres guidance was a condition of the law. As in England, this was not the case.

This method of governance through a fusion of public health advice and criminal laws has several benefits from the perspectives of the UK Government and regional executives. It provides scope for governments to afford greater potency to their public health advice through the suggestion that it is backed by the force of law. Correspondingly, when it suits the government, in enables them to emphasise individual discretion and responsibility as part of a more permissive public health situation. Achieving this through changes to guidance rather than law has the benefit of versatility by enabling a considerable degree of rule-modification without incurring the political and logistical costs of formal amendment to the underlying law. The overlay of guidance also enabled the Government to communicate and present messages in the manner thought to be most effective to achieve the public health goals, informed by insights from behavioural science, which is an opportunity not afforded by the techniques of legislative drafting.

There is also a deeper more fundamental aspect of the advantage gained by governments in adopting this technique. The fusion of law and guidance operates a mechanism for centralising power in the hands of the executive that would otherwise be more widely dispersed within our constitutional arrangements. Thus, as we have seen, the Government has no constitutional role in interpreting the criminal law. Only the courts can pronounce on the meaning of the criminal law. Other public authorities whose responsibility it is to enforce the criminal law can and do sometimes produce guidance on their understanding and approach to the criminal law, namely, the police and prosecuting authorities. But the Government has no role in enforcing the law either under the general law or under the regulations. The separate and prior task of making law, especially criminal law, is one which rests primarily with Parliament (and regional legislatures in the context of the regional governments). Whilst the

59 C. Salmond, "First Minister lifts exercise rule in Scotland's lockdown", The Scotsman, 10 May 2020 (available at https://www.scotsman.com/news/politics/first-minister-lifts-exercise-rule-scotlands-lockdown-2848321 [Accessed 4 June 2020]). 
Government does have powers delegated by Parliament to make law, these must still be laid before and approved by Parliament. ${ }^{60}$ Even the promulgation of public health advice is not something that central government would ordinarily do. Public health advice is ordinarily provided by the health service at a national or local level. The NHS has a website that sets out detailed advice on a very wide range of public health issues and indeed this was a resource that was initially used by the Government to provide public health advice in response to the coronavirus pandemic, before public health advice and legal regulation became folded together. The coronavirus guidance has therefore operated as a method of concentrating these ordinarily diffuse sources of authority - interpreting the law, making the law and promulgating public health guidance - in the hands of central government. This enabled the government to promulgate a sui generis system of rules and exceptions to fit the prevailing public health situation. Whilst not necessarily illegitimate, this distinctive and highly potent form of emergency rule sits outside the legal regime established by Parliament for emergency governance contained in the Civil Contingencies Act 2004. It represents the creation of a new form of emergency regulatory intervention.

Governance through guidance even in normal conditions raises significant question marks. Judicial consideration of the use of guidance as a form of regulatory intervention is, as has been noted, still relatively nascent and the principles remain underdeveloped. Strikingly however in BAPIO Action, the House of Lords was critical of the informal way that the Government had sought, through the use of guidance, to impact people's rights and opportunities, in that case the employment and training opportunities of international medical practitioners. Lord Bingham pointed out that the guidance at issue in that case had not been "issued" in any formal sense. It had been published on the NHS website and no official draft, record or statement had been identified. Lord Bingham observed that it "is for others to judge whether this is a satisfactory way of publishing important governmental decisions with a direct effect on people's lives." ${ }^{61}$ Whilst the court did not suggest that the lack of formality affected the lawfulness of the guidance, the criticism was clear. It is criticism that applies with even greater force in the context of the coronavirus guidance because its impact on individual

\footnotetext{
${ }^{60}$ For an excellent account on the marginalisation of Parliament during the pandemic see K. Ewing "Covid-19: government by Decree" Kings Law Journal, Vol. 31 No 1, 1-14 (2020); and also on the increased role of Parliament that would have been entailed by the use of the Civil Contingencies Act 2004: A. Block and C. Walker, "Why did government not use the Civil Contingencies Act?" Law Gazette, 2 April 2020.

${ }^{61} R$ (BAPIO Action Ltd) $v$ Secretary of State for the Home Department [2008] UKHL 27, [2008] 1 AC 1003, paragraph 10.
} 
freedom was far more extensive. The publication of an official text, recording amendments, would enhance transparency and facilitate scrutiny by Parliament, by society and by courts.

Indeed, one of the impacts of the use of the coronavirus guidance to manage the coronavirus pandemic more generally that it has marginalised the role of Parliament in scrutinising the rules and holding Government to account. Parliament's role was already reduced by the Government's use of emergency procedure in making and amending the Regulations, which meant that they were not laid before Parliament before they were made and Parliamentary consideration was much delayed. ${ }^{62}$ However, it was not the Regulations but rather the coronavirus guidance that was the primary source of the instructions given to the population and since it was published informally on the government website it was not even laid before Parliament. Only one of the associated documents, the Government's recovery strategy, was laid before Parliament as a Command Paper. There are many examples of statutes requiring documents to be laid before Parliament (known as "Act Papers") and the use of guidance in an emergency to regulate people's lives is a context in which, if guidance is appropriate at all for such a role, it should be subject to a requirement that an official version, approved at Ministerial level, should be laid. ${ }^{63}$

Perhaps the most immediate and visible consequence of Government's use of guidance containing a fusion of public health advice and information about criminal laws to manage the coronavirus crisis has been the resultant confusion and misunderstanding about the rules and their status. This is reflected in the numerous examples, particularly in the early stages of the lockdown, of police forces enforcing public health advice rather than law, such as the actions of Derbyshire police publishing drone footage on Twitter seeking to prevent people driving to take exercise. ${ }^{64}$ The level of misunderstanding of the nature of the instructions being promulgated by the Government in the general population is reflected in the results of the survey conducted by Halliday, Meers and Tomlinson, which, in addition to the result already mentioned, found that $56 \%$ of the people surveyed thought that driving to open spaces was

\footnotetext{
${ }^{62}$ See above note 32 above.

${ }^{63}$ On Act Papers and Command Papers see Erskine May online, paragraph 7.30 (available at https://erskinemay.parliament.uk) [Accessed 15 June 2020]. Ordinarily Act Papers are approved by Department, Command Papers are approved by Ministers.

64 H. Shearing, "Stay local to exercise, says government" BBC News, 27 March 2020 (available at https://www.bbc.com/news/uk-52062209 [Accessed 4 June 2020]); and see J. Ames, "Lord Sumption warms against police overstepping limits" The Times, 31 March 2020 (available at https://www.thetimes.co.uk/article/lord-sumption-warnsagainst-police-overstepping-limits-6wk2k335k [Accessed 4 June 2020]). See also the examples above note 52.
} 
banned, when it was not, and $76 \%$ thought shopping more than once per day was banned, when it was not. ${ }^{65}$

The biggest casualty of the Government's approach has, however, been respect for individual autonomy. Since respect for individual autonomy is central to the legitimacy of government action this should be of profound concern. It has been shown that the Government used the coronavirus guidance as a means of communicating a particular perspective on and interpretation of the legal rules and their relationship to public health advice to the population at large. In this way the Government sought to "frame" individual decision-making and behaviour during the lockdown. But it has been shown that this framing failed to make clear the respects in which individual choice was restricted by law and the respects in which individuals remained free to choose how to act but where government advice was relevant to their decision. People were therefore unable to make properly informed decisions with a clear understanding of what the law said, what it did not say and what the public health guidance was. The vast majority of the population took their instructions either directly from the coronavirus guidance or the reporting of the guidance in the media. People cannot be expected to engage in the complex and time-consuming task of consulting other sources to identify and clarify the Government's instructions, in particular where this requires consulting legal instruments in their native format. This is more especially the case in the context of a hugely stressful public health emergency when the population was attempting to adapt to unprecedented upheavals and crises in their day-to-day lives, with the ever-present overriding fear of coronavirus itself. In such a context clarity and transparency were especially important.

Of course, the negative impact on individual autonomy occurred in an effort to combat a major public health crisis and it might be argued that it is therefore justified. ${ }^{66}$ However, the Government has itself emphasised the desirability of transparency and clarity in responding to emergencies. In 2013, for instance, a Cabinet Office publication on responding to emergencies emphasised that policies, plans and practices should be explained to the public "comprehensively, clearly and consistently, in a transparent and open way."67 There can moreover be no justification for providing inaccurate or misleading information to the

\footnotetext{
${ }^{65}$ Halliday, Meers and Tomlinson, "Public Attitudes on Compliance with COVID-19 Lockdown Restrictions", U.K. Const. L. Blog, 8th May 2020 (available at https://ukconstitutionallaw.org/2020/05/08/simon-halliday-jed-meers-and-joe-tomlinsonpublic-attitudes-on-compliance-with-covid-19-lockdown-restrictions/ [Accessed 4 June 2020]).

${ }^{66}$ That does not take away from the fact that it is important to appreciate that there has been a substantial impact on individual autonomy which requires justification.

${ }^{67}$ Cabinet Office, Responding to Emergencies, The UK Central Government Response, Concept of Operations (2013) Ch. 6, para. 2.5.
} 
population, even in an emergency, and we have seen that at least some important aspects of the coronavirus guidance merit this description. Some of the errors in the coronavirus guidance identified in this paper were sufficiently inaccurate that the courts would probably have stepped in to correct the way that the law was being portrayed had they been invited to do so (and had the timescales involved not made judicial review more than usually difficult to make effective). ${ }^{68}$

We must also briefly consider one further aspect of the phenomenon under consideration: its relationship to the concept of nudging, which has received a considerable amount of public attention during the coronavirus emergency given the Government's reliance on experts in behavioural science. ${ }^{69}$ As anyone familiar with the concept of nudging will know, there are circumstances in which governments can legitimately choose to present information in a manner that frames individual choice knowing and intending that it will influence behaviour in a predictable and desired way even where this is intended to lead people to overestimate or underestimate risks. This can occur, for example, when producers of foodstuffs are required to present information in a certain way, e.g. the fat content of products as $10 \%$ fat rather than $90 \%$ fat free, or where the government presents the risk of death from a certain behaviour as increasing tenfold rather than increasing from $0.001 \%$ to $0.01 \%$, or the use of vivid unpleasant imagery on packaging. ${ }^{70}$ Such techniques are just some of very many techniques known as "nudges", ${ }^{71}$ which is a recognised form of governance in the UK and elsewhere. $^{72}$

The Government's approach to the coronavirus guidance, including the manner that information and instructions were portrayed, was no doubt influenced by insights of behavioural science, the same insights that inform nudges. ${ }^{73}$ However, the phenomenon under

\footnotetext{
${ }^{68}$ See e.g. Gillick $v$ West Norfolk and Wisbech Area HA [1986] AC 112 and R (Equality and Human Rights Commission) $v$ Prime Minister, [2011] EWHC 2401 (Admin), [2012] 1 WLR 1389.

\begin{abstract}
${ }^{69}$ The Government's reliance on behavioural science insights in its response to the coronavirus outbreak became controversial in later March when it was reported that the delay in imposing lockdown measures was based on advice that people would suffer "behavioural fatigue". This led to a number of behavioural scientists writing an open letter in protest. See R. Chataway, “Can we 'nudge' away Coronavirus?" BVA Nudge Unit, 20 March 2020 (available at https://bvanudgeunit.com/can-we-nudge-away-coronavirus/ [Accessed 4 June 2020]).
\end{abstract}

${ }^{70}$ C. R. Sunstein, “The Ethics of Nudging” (2015) 32 Yale Law Journal 414.

${ }^{71}$ The concept was popularised by R. Thaler and C. Sunstein, Nudge (New Haven: Yale University Press, 2008).

${ }^{72}$ See for a good summary, House of Lords Science and Technology Committee, Behavioural Change Report (TSO, 2011) HL $179, C h .2$, including a reference to the Government's view that nudging excludes information and promotional forms of nonregulatory interventions as these do not involve promoted choice.

${ }^{73}$ A key lesson learnt from the swine flu pandemic was identified in Government contingency plans as "the potential to use insights from behavioural science better." Department of Health, England and Health Departments of the Devolved 
examination in this paper is fundamentally different from nudging. A nudge leaves a choice open. ${ }^{74}$ It is distinct from a regulatory intervention which prohibits conduct or imposes disincentives on certain behaviour. ${ }^{75}$ Changing the individual's scope of free choice to forbid or restrict choice is in fact the antithesis of a nudge. The imposition of a criminal law framework under the Regulations creates a regulatory intervention that prohibits certain activities through deterrence. By obscuring the scope of the relevant rules through normative ambiguity and authoritative statements by the Government on the content of these rules, the Government has extended the deterrence effect associated with the criminal sanctions underlying the Regulations to encompass pieces of public health advice. These, too, control people's perception of their scope for individual choice and thus cannot be described as nudging. The Government is consequently engaging in a complex form of regulatory governance, not a form of nudging. ${ }^{76}$

At the end of May 2020 this issue took an unexpected turn when the Prime Minister's chief adviser, Dominic Cummings, was revealed to have left London with his wife and child shortly after the lockdown was imposed, and indeed the day after the Regulations came into effect, on 27 March 2020, to travel to Durham to stay close to his parents on their estate. In an unprecedented televised public statement made in an effort to explain his actions, $\mathrm{Mr}$ Cummings also admitted to having travelled to Barnard Castle on 12 April in a car with his wife and young child, a journey he said was an effort to test his eyesight following his recovery from Covid-19. The revelations provoked a media storm and there was an enormous amount

Administrations of Scotland, Wales and Northern Ireland, UK Pandemic Influenza Communications Strategy 2012 (2012), $p$. 16. See more generally, Public Health England, Improving people's health: Applying behavioural social sciences to improve population health and wellbeing in England (Crown Copyright September 2008, gateway number 2018478).

${ }^{74}$ Thaler and Sunstein, Nudge (New Haven: Yale University Press, 2008): Thaler and Sunstein's well known definition, which is wider than is now commonly accepted, is: “... any aspect of the choice architecture that alters people's behaviour in a predictable way without forbidding any options or significantly changing their economic incentives.” (p.6).

${ }^{75}$ House of Lords Science and Technology Committee, Behavioural Change Report (TSO, 2011) HL 179, 2.3, helpfully distinguishes between the following interventions: regulatory governance (restrict/eliminate choice); fiscal measures (incentives/disincentives); other incentives and persuasion; and choice architecture (nudges). This builds on the Nuffield Ladder of Interventions (Nuffield Council of Bioethics, Public health: the ethical issues, (Nuffield Council of Bioethics: London 2007)). A more comprehensive description of behavioural change interventions is the Behavioural Change Wheel: S. Michie, M.M. van Stralen, R. West, "The behaviour change wheel: a new method for characterising and designing behaviour change interventions" (2011) 42 Implementation Science 6.1.

${ }^{76}$ Public health guidance published to assist people to avoid contracting or transmitting disease, which sets outs out an authoritative non-legal normative framework, backed by health incentives, is also not well characterised as a nudge (although it strictly satisfies Thaler and Sunstein's definition). The manner that public health advice is presented would fall within the concept. On the boundaries of nudging and controversies surrounding the concept, see R. Baldwin, "From Regulation to Behavioural Change: Giving Nudge the Third Degree" (2014) 77 Modern Law Review 831 and in the context of health care, C. Perry, K. Chhatralia, D. Domesick, S. Hobden, L. Volpe, "Behavioural insights in health care, Nudging to reduce inefficiency and waste" (The Health Foundation, December 2015). 
of public anger when the Prime Minister announced that he was satisfied Mr Cummings had not broken the law and had exercised his judgment appropriately. ${ }^{77} \mathrm{He}$ said that the trip to Durham had been motivated by a concern about childcare as Mr Cummings' wife had been unwell and Mr Cummings himself feared he might succumb to coronavirus. Mr Johnson stated that Mr Cummings "followed the instinct of every father and every parent". For the population at large it appeared that a different law was being applied to Mr Cummings than had been applied to everybody else. But the intensity of public anger was in large part a reflection of the manner that the coronavirus guidance had presented the legal rules, overstating their stringency. In the early phase of the lockdown the coronavirus guidelines had been clear that there were four reasons only for leaving home, shopping, working, exercise and medical need and that leaving home other than for the specified reasons would be unlawful. The population had taken the guidance at its word and had followed it, often at the cost of huge personal sacrifice. The guidelines had given no indication that there was room for an element of individual discretion or judgement and by suggesting that it had been open to Mr Cummings to exercise his judgement as a parent, the Prime Minister's position seemed incomprehensible. The root issue exposed by the Cummings affair was therefore not the unequal application of the law but the fact that the Government's response to the pandemic had failed to respect individual autonomy by overstating the stringency of the criminal law restrictions on personal freedom.

\section{Conclusion}

This paper has explained how the United Kingdom Government's response to the coronavirus pandemic during the critical lockdown phase between 23 March 2020 and 1 June 2020 involved the coordination of individual behaviour through a potent fusion of public health advice and the criminal law in the form of the coronavirus guidance. The coronavirus guidance was used by the Government as the principal tool for controlling the public understanding of the restrictions on individual freedom that were in place. However, the guidance was extremely ambiguous and unclear as to the nature of the instructions that it communicated. Some aspects of this resulting ambiguity were subtle and unobjectionable but other aspects, highlighted in this paper, misrepresented the scope of the criminal law restrictions. This may well have been

77 See eg Johnston, “Boris Johnson says Dominic Cummings 'acted legally, responsibly and with integrity' in lockdown row”, Politics Home, 24 May 2020 (available at https://www.politicshome.com/news/article/boris-johnson-says-dominiccummings-acted-legally-responsibly-and-with-integrity-in-lockdown-row [Accessed 4 June 2020]). 
the product of oversight, error, or a well-intentioned effort by officials to produce clear messages, but the result was that people were relying on information that was in fact unreliable. It was unreliable because it failed to accurately and clearly set out what the true limits on individual liberty were. The coronavirus guidance developed into a powerful new, sui generis form of emergency regulatory intervention outside the system of emergency government set out by Parliament. Whether this is an appropriate way to govern in an emergency at all is a larger question than this paper can address, although it is hoped that the analysis here will inform and possibly kickstart an examination of that question. It is after all an urgent question. At the time of writing, the coronavirus guidance continues to perform the central role of communicating instructions to the population in England and similar guidance applies in other parts of the United Kingdom.

The analysis of the coronavirus guidance set out in this paper suggests that if guidance is to be used as a form of emergency regulation it should at the very least be firmly and expressly located in a statutory framework that sets out conditions on the use of the power, including a requirement that the guidance and any amendments are approved at Ministerial level and laid before Parliament. Moreover, at a minimum, such guidance should conform to the following substantive principles of transparency to enable people accurately to understand the rules that they live by during a public health emergency: (1) guidance should clearly distinguish information about the law from public health advice; (2) all underlying or associated legal instruments should be clearly and accurately identified and an accurate link to a copy of the up-to-date law should be provided; (3) information about the law should be accurate and complete; (4) where the law is too complex to be set out in full the fact that the account is partial should be made clear and key parts of the law (such as in the present case, the "reasonable excuse" exception) should not be omitted; (5) guidance should make clear when opinions are offered about the interpretation of the law and the status of such opinions; (6) guidance should not suggest that instructions are based on law when they are not.

These six principles might be thought to be rather obvious. If that is so, then it is even more concerning, perhaps even alarming, that in the critical early period of the coronavirus lockdown in England, when the most severe restrictions on individual liberty in modern times were in place, the coronavirus guidance failed to comply with every one of them. 